\title{
Estudio de la Figura de Las Sociedades Unipersonales, Surgimiento y Antecedentes de su Implementación en Europa y Latinoamérica, Además del Análisis de su Introducción a la Legislación Hondureña
}

Gabriel Alejandro Ochoa Quiroz *

Sumario: Introducción, Surgimiento de las Sociedades Unipersonales, Conceptualización, Implementación en Europa, Implementación en Latinoamérica, Introducción a la Legislación Hondureña de la Sociedades Unipersonales, Análisis de la Introducción de la Sociedad Unipersonal en nuestro Marco Legal, Conclusiones

\section{Resumen}

La Figura de Sociedades Unipersonales fue introducida en la Legislación Hondureña recientemente por el Decreto $\mathrm{N}^{\circ}$ 284-2013 en la cual se manifiesta que las Sociedades Regidas por El Código de Comercio podrán ser creadas por un Socio lo cual es un hecho de bastante consideración en nuestro marco legal.

Esta reforma abre un panorama diferente al permitir más libertades en las personas que están interesados en crear negocios propios sin la necesidad de tener que asociarse, lo cual es un empuje a nuestra economía pero que también se debe analizar por su concepción innovadora y para algunos contradictoria a la doctrina societaria que es conocida en nuestro ámbito legal.

Así mismo hay que hacer referencia el porqué del surgimiento de dicha figura en la Legislación y Doctrina Mundial, y lo más Importante que si en el decreto que se introdujo a nuestro marco legal se tomaron en cuenta todos los elementos de dicha Modalidad para su correcto funcionamiento en nuestro Sistema Mercantil.

Palabras Clave: Sociedad Unipersonal, Sociedad Unimembre, Empresa Individual de Responsabilidad Limitada

\section{Abstract}

Figure of Unipersonales Societies was introduced recently by the Honduran Law Decree No. 284-2013 which states that in societies governed by the Commercial Code may be created by a Member which is a fact quite account in our legal framework.

This reform opens a panorama completely allow more freedoms for people who are interested in creating your own business without the need to associate with, which is a boost to our economy but can also be analyzed for its innovative design and some contradictory the corporate doctrine which is known in our legal field.

Also reference should be made because of the emergence of this figure in Legislation and World Literature and most Important that if the decree was introduced to our legal framework taking into account all the elements of that mode for proper operation our Mercantile System.

Keywords: Sole Society, Unimembre Society, Individual Limited Liability Company

* Abogado graduado de la Faculta de Ciencias Jurídicas de la Universidad Nacional Autónoma de Honduras 


\section{INTRODUCCIÓN}

La Figura de las Sociedades Unipersonales es una modalidad de Sociedad o entidad comercial la cual desde hace mucho tiempo se han venido desarrollando en diversas partes del mundo con el fin de incentivar la inversión interna en los países, evitar algunas anomalías en las constituciones de Sociedades y crear una nueva opción a los interesados en emprender en el comercio.- Si bien es cierto al escuchar el término de "Sociedades Unipersonales" en nuestro ámbito jurídico local, el mismo carece de notoriedad suficiente, la concepción de dicha modalidad tuvo sus orígenes entre juristas y legisladores en el continente de Europa a principios del siglo pasado y aun mas las primeras implementaciones de dicha figura o similares en países vecino también tiene un largo tiempo de haber sucedido.

Por tanto, en el desarrollo del presente artículo se busca ofrecer nociones básicas con relación a las implicaciones sobre las cuales se debe regir una Sociedad Unipersonal, los factores que han influido para su adopción en diversas legislaciones, como también, el impacto que dicha figura mercantil tendría en el marco legal de nuestro país.

Así mismo como la viabilidad de dicha figura en el desarrollo de nuestro comercio, todo esto con el fin que el lector pueda tener una impresión clara y comprensible de que es y que comprenden las Sociedades Unipersonales que ahora forman parte de la actual Legislación.

\section{METODOLOGÍA}

Se optó por utilizar en el presente artículo, un diseño de investigación Exploratoria-Descriptiva basado en el paradigma Positivista, donde el principal enfoque es la recolección de información con revisión documental para establecer un desarrollo cronológico del tema principal, su evolución y el contraste entre diferente posturas de los autores consultados con el fin de poder separar y determinar los elementos que son constituyentes del surgimiento de las Sociedades Unipersonales.
Así mismo se hizo de uso de metodología comparativa entre las diferentes posturas que se establecieron para introducir dicha figura en las diversas legislaciones que en la actualidad la han adoptado en su derecho positivo con el fin de hacer una breve análisis de los elementos que aun son debatidos o contradecidos por muchos juristas que no ven conciben el concepto de Sociedad Unipersonal por completo.

\section{SURGIMIENTO DE LAS SOCIEDADES UNIPERSONALES}

Para departir con relación a una sociedad mercantil, debemos iniciar con la forma en que dicho concepto puede ser concebido en nuestra comunidad jurídica, a lo cual nos retrotraemos a sus inicios en Europa donde se empezó a reconocer dichas sociedades bajo ese término, entendiéndose principalmente como un grupo de personas que se reunían en principio para desarrollar trabajos en común en el marco de la revolución industrial ${ }^{l}$.

Históricamente, las primeras sociedades que existieron a nivel mundial fueron las cooperativas, colectivas y las comanditas, cuya naturaleza jurídica residía sobre un carácter personalísimo como lo es hoy en día, posteriormente aparecen las sociedades capitalistas, destacando por excelencia la Sociedad Anónima y la de Responsabilidad Limita, las cuales surgieron como un hibrido ante la necesidad de las sociedades o empresas familiares pero con la protección de la limitación de responsabilidad.

El esquema o la estructura de la Sociedad como figura del derecho mercantil que actualmente conocemos, fue evolucionando hasta llegar a convertirse en un Contrato de tipología multilateral, donde dos o más personas pactan crear una persona jurídica la cual ejercerá actos de comercio y será independientes de ellos tanto de sus actos como de su patrimonio, siempre y cuando los socios no comentan actos viciados referente a los actos de la Sociedad o en su patri-

\footnotetext{
1 (Castañeda 2007)existía en los asalariados un desventaja considerable frente a sus patronos producto de la Revolución Industrial y, gracias a los apuntes doctrinales de Owen en relación al proyecto de reforma social para remediar las desventuras y desdichas de los

trabajadores, se tradujo en las primeras sociedades cooperativas de producción y consumo, legislación obrera y organizaciones de trabajadores.
} 
monio que pueda afectar a terceros.- Dicha planteamiento de la Persona Jurídica es atribuida en principio por algunos a Saviyng ${ }^{2}$ cuyo elemento es inherente a las sociedades en general, mismo que será de gran discusión como a continuación presentaremos en este artículo investigativo.

Ahora bien, la concepción de Sociedad en su inicios nace con el propósito de regular costumbres mercantiles en el ámbito comercial, pero en cuanto a su uso, estas surgieron de los quehaceres que trastocaban su esencia y en un intento de regular dichas acciones nace la Sociedad Unipersonal.

Asimismo los comportamientos que viciaban las mismas y la forma en que los juristas o comerciantes de la época resolvían diversas problemáticas motivan la creación de éstas sociedades.- A finales del siglo XIX y principios de siglo $X X$, más específicamente, se habían instituido prácticas para gozar de la protección del patrimonio propio y sólo responder con el capital que se invertía en la actividad comercial, las personas constituían Sociedades donde para cumplir el requisito del número de socios incluían familiares, testaferros u otras personas las cuales solo comparecían para llenar el requisito legal pero en realidad no tenían nada que ver con el desenvolvimiento de las sociedad, las cuales fueron conocidas como sociedades de hecho o sociedades de favor ${ }^{3}$.

Tales situaciones eran contrarias a la naturaleza de una Sociedad por no ser el reflejo de un interés colectivo, si no sólo un interés individual y en la mayoría de los casos eran también las aportaciones, las que pertenecían en su totalidad en el socio que se encargaría de la administración del negocio.

Bajo ese contexto, nos daremos cuenta que la dinámica utilizada a través de la historia, no se alejan de la realidad y aun

\footnotetext{
2 (Castañeda 2007) Años más adelante Savigny bosqueja la teoría de la ficción que es continuada por su discípulo Puchta. La teoría de la ficción propugnaba que el individuo podía transferir su capacidad jurídica a algo externo, creándose así una persona jurídica distinta de los que la constituyeron

3 (Sanabria, 2008) Igualmente, los casos no poco frecuentes de las llamadas sociedades de favor, en las que no todos los socios compartían una verdadera intención de configurar el negocio jurídico societario, llamaron la atención de la doctrina que entonces optó por regular este tipo de prácticas a efectos de rescatar la función practico social que debe cumplir la sociedad mercantil
}

se presentan en nuestra realidad sociedad; es por ello que los juristas de ese tiempo empezaron a estudiar la posibilidad que una persona que decidiera emprender un negocio y por el temor que tuviera que responder con todo su patrimonio no tuviera que caer en dichas prácticas para valerse de situaciones manipulas y gozar con lo que hoy en día conocemos como responsabilidad limitada o velo corporativo.

Así entonces se empieza a concebir la idea de una figura que le permitiera al comerciante realizar sus acciones de comercio con la separación de su patrimonio y del negocio o bien que se gozara de responsabilidad limitada en los actos de comercio ejercidos.- Estas teorías en principio se le atribuyen al juristas Paul Carry, posición que fue desarrollada posteriormente por el Jurista Austriaco Oskar Pisko.

Las teorías establecidas por Pisko fueron introducidas en la legislación del Principado de Liechtenstein en el año de 1926, donde se establecieron tres figuras, la Empresa Individual de Responsabilidad Limitada, el Anstalt y la Sociedad de Personas o Capital de una sola persona ${ }^{4}$, la primera figura de la Empresa Individual de Responsabilidad Limitada es la solución de Pisko ${ }^{5}$ para que el empresario pudiera establecer una actividad comercial determinada siempre con el aseguramiento o separación de su patrimonio propio y del patrimonio o capital que respondiese por las responsabilidades adquiridas por el negocio sin que y no se desfiguraba la teoría clásica del pluralismo del pacto social ya que no era una sociedad lo que se constituía sino que simplemente se regulaba la actividad comercial y se le dotaba de una especie de reconocimiento o personalidad a dicho negocio y sujetado a una serie de normas que aseguraban el patrimonio del negocio para la no afectación de terceros.

\footnotetext{
4(Lehuedé, 2011) Con ocasión de una importante modificación al Código Civil del Principado de Liechstenstein en materia de sociedades y personas jurídicas, verificada mediante ley de 20 de enero de 1926, se incorporaron al señalado Código novedosas herramientas de gestión para el empresario e inversionista individual, distintas a todas las conocidas hasta el momento: la empresa individual de responsabilidad limitada (Einzelunternehmung mit beschränkter Haftung), la figura del "Anstalt" y la sociedad de personas o de capital con un solo socio (Einmannverbandspersonen).
}

5 (Sanabria, 2008) la exigencia al empresario de desembolsar la totalidad del patrimonio desde un momento previo al inicio de la ejecución de las actividades empresariales, así como también mediante la destinación exclusiva 
Podemos observar, que si bien se aceptaba que un comerciante o empresario iniciara un negocio con protección de su patrimonio, el hecho de contradecir el concepto de Sociedad como se conocía aún, era un elemento muy sensible de decidir, es por eso que al principio en otros países se optó por los patrimonio de afectación, es decir que un Empresario constituyera un determinado patrimonio o capital el cual se usaría para realizar actos de comercio y que su responsabilidad estaría supeditado al capital suscripto.

Se puede denotar que en dichas tesis no solamente se obviaba el uso de la palabra Sociedad si no que también no se le atribuía al tal figura o acto constitutivo de comercio el elemento de la Persona Jurídica, esto también fue discutido ampliamente si debía crearse dichas figuras que además del patrimonio de afectación también constituían un ente diferente 0 una persona de derecho ajena de sus creadores.

En lo que respecta a las Sociedades de una persona, fue donde se creó el mayor estudio y debate ya que contradecían lo establecido en una Sociedad mercantil, pero manifestaban posiciones donde se plateaba que dicho concepto no debía limitarse a las sociedades como un conjunto de dos o más personas, sino más bien a una sociedad en si misma o en su finalidad comercial como un medio por el cual se establece un negocio y que tal cuenta con una personalidad jurídica, una identidad independiente a la de los socios que la conforman.

Es por eso que al observar que en la práctica, dichas sociedades eran la visión y esfuerzo de una sola persona y que la necesidad de que otra fuera socia, era algo meramente de tramite y no necesario para la realización de tal fin, es ahí donde se empieza a plantearse si una Sociedad contemplaba la legalización de un pacto o Contrato Multilateral o la legalización de un acto de comercio por lo cual es indistinto del número de socios que ésta pueda contener, debiendo considerarse únicamente el hecho de que ese negocio o esa empresa, fuese iniciada por una persona regulada por la legislación.

Esto idea fue planteada para que el derecho mercantil estuviera acorde al desenvolviendo del comercio en ese momento y que brindara esa opción a los empresarios que se sintieran con la capacidad necesaria para emprender un negocio o actividad comercial, y más aun que tuvieran la posibilidad que en el futuro su visión de comercio plasmada en una so- ciedad, pudiera tener la participación de terceros como socios, esto con la intención de desfigurar la concepción del negocio o fin original.

Aun así, existían otras inquietudes que visualizaban los detractores y escépticos de esta nueva forma de sociedad, su manejo, toma de decisiones y la administración de estas sociedades si éstas eran dirigidos solamente por una persona y si esta misma persona tomaría de forma absoluta, las decisiones que afectaran a la sociedad, lo cual fue ampliamente discutido en la legislación Francesa y dichas situaciones que con establecer las respectivas normas que establecieran controles más rigurosos y condiciones donde si el socio único las transgredía perdería su responsabilidad limitada y se volvería responsable solidario ante los terceros que se viesen afectados por dichas acciones es que fue tomando forma toda la doctrina que envuelve a la Sociedad Unipersonal.

Uno de los últimos debates de cual aún es motivo de discusión, si esta clase de sociedades pueden ser aplicables a las sociedades anónimas, es decir, por la forma del funcionamiento de una Sociedad Anónima y su finalidad meramente capitalista. Muchos establecen que realizar una Sociedad Anónima Unipersonal, es contraria a la finalidad de la misma sociedad, siendo algunos de sus argumentos que la Sociedad para su funcionamiento necesita contar con Órganos encargados de controlar estas sociedades, elemento que sería difícil para su conformación al solamente poseer únicamente un Socio.

Asimismo, otro elemento a discutir, es si al momento de su creación los estatutos de la misma serían diferentes al de una Sociedad con dos o más socios, en situaciones donde se contempla básicamente la participación en plural.- Si bien estos argumentos tienden a tener un peso una vez llevados a la práctica, sobre todo lo referente al funcionamiento de Sociedades Anónimas Unipersonales.

\section{CONCEPTUALIZACIÓN}

Al tratar de tener un concepto claro de que es una Sociedad Unipersonal, se puede observar una constante en los elementos o premisas que conforman su conceptualización para diferentes autores y su tipificación en algunas leyes como ser: 
Las Sociedades Unipersonales; son las fundadas o constituidas por un sólo socio, el cual tiene toda la participación social 0 acciones en su persona y según la naturaleza de su creación, o en su defecto a la originada a raíz de la reducción de socios en una sociedad en general.

Estos dos elementos como anteriormente se dijo son una constante cada vez que se trata de establecer una Sociedad Unipersonal o Unimembre como también se conoce, una definición basada en estos elementos como la existente en la Ley de Sociedades de Capital de España ${ }^{6}$ puede interpretarse como contradictoria con la teoría conocida sobre las sociedades, y es que lo plateado por las leyes y la doctrina, que una sociedad es el pacto social y multilateral que existe entre dos o más personas con un fin comercial o mercantilista en común, por lo cual al concebir la idea de una sociedad de un sólo socio no encaja en dicho planteamiento.

\section{IMPLEMENTACIÓN EN EUROPA}

Tal como lo hemos afirmado, la primera incorporación de las Sociedades Unipersonales fue bajo el Principado de Liechtenstein, pero encausó su estudio y posterior implementación en diversas legislaciones en buena parte de los países europeos. Alemania, lo incorporó a su legislación en el año 1980 aunque en dicho país su doctrina lo contemplaba desde el siglo XIX.

España por su parte, lo estableció con las reformas a su Ley de Sociedades de Capital donde establece la creación o bien la sobrevenida de Sociedades de Responsabilidad Limitada y Sociedades Anónimas unipersonales las cuales llevaran las siglas de SLU y SAU respectivamente, donde éstas pueden llegar a ser constituidas por personas naturales o jurídicas, mas una serie de normas de cómo deberían llevarse a cabo su registro, obligaciones, contrataciones contraídas,

6 Ley de Sociedades de Capital de España

Artículo 12: Clases de sociedades de capital unipersonales.- Se entiende por sociedad unipersonal de responsabilidad limitada o anónima:

a) La constituida por un único socio, sea persona natural o jurídica.

b) La constituida por dos o más socios cuando todas las participaciones o las acciones hayan pasado a ser propiedad de un único socio. Se consideran propiedad del único socio las participaciones sociales o las acciones que pertenezcan a la sociedad unipersonal. las consecuencias por el incumplimiento de las mismas que acarrean la responsabilidad solidaria del socio la preponderancia de la Publicidad en su actividades.

Otros países que fueron más reacios a su introducción, Francia por su tradición doctrinaria, las incorporó a su legislación hasta el año de $1977^{7}$, de igual manera Italia en el año 1993 dio curso a la implementación de Sociedades Unipersonales pero únicamente de Responsabilidad Limita, en esta línea de países también se encuentra Portugal, Holanda, Bélgica, Luxemburgo y con la particularidad que en Noruega son permitidas siempre y cuando sea el Estado el socio único.

En Inglaterra son permitidas tras el conocido caso de Salomón \& Salomón y que en la actualidad bajo la reforma de la "Company Regulation Act" funcionan bajo la denominación "Limite Prívate Companies" a diferencia de las sociedades de plurales que se denominan "Public Companies" 8 .

De igual forma en el derecho anglosajón surge bajo el concepto de Wholly Owned Subsdiaries donde el único socio muchas veces es el Estado, asimismo estas figuras societarias son utilizadas cuando el único socio de la Compañía es otra sociedad ${ }^{9}$ la cual utiliza a la Wholly como una filiar o para realizar determinada actividad.

Siguiendo esta línea del derecho Anglosajón en Estados Unidos de Norteamérica, el sistema permite que una o más

7 (Porras, 2012) Con ese hecho, la legislación francesa relativa a las sociedades unimembres fue cediendo terreno hasta que en 1977 se propuso la Ley 556, la cual admitía la sociedad originariamente unipersonal, con la finalidad de hacerle frente a la anarquía existente en el pequeño comercio, y con ello limitar la responsabilidad del empresario, evitar o disminuir las sociedades ficticias y permitir la existencia de mejor administración y gestión de la sociedad, así como perfeccionar el régimen de cesión y transmisión de empresas.

Posteriormente, en 1985 se reforman las nociones de sociedad que contenía el artículo 1832 de su Código Civil, así como el artículo 34 de la Ley 66-537, dando cabida, por la ley 85-627, a la figura de empresa individual de responsabilidad limitada.

8 (Lehuedé, 2011) En Inglaterra, por su parte, la Companies Regulations Act de 15 de julio de 1992, por transposición de la Directiva 89/667/CEE, autoriza a constituir y mantener una sociedad con un solo socio en las denominadas Limited Private Companies, manteniéndose en cambio el requisito de la pluralidad fundacional en las Public Companies y en las Unlimited Private Companies28

9(Sanabria, 2008) igualmente y en el mundo anglosajón se fueron presentando figuras como las de las compañías subsidiarias completamente controladas por la matriz (wholly owned subsidiaries) en donde había una propiedad societaria única y completa a efectos de ejercer un control sobre la misma 
personas o corporaciones nacionales o extranjeras puedan fundar una Corporación o empresa esto mediante reformas realizadas en el año 1962 que fueron adoptadas por varios Estados.

\section{IMPLEMENTACIÓN EN LATINOAMÉRICA}

En nuestro continente, países como Chile, Colombia, Paraguay y Costa Rica se han optado por introducir la figura de Empresa Individual de Responsabilidad Limitada, esto con el fin de no contradecir su doctrina interna de la definición de una Sociedad más lo establecido en sus leyes donde se establece la Sociedad como un pacto o contrato entre dos o más personas, lo cual es una concepción o puntos básicos que se comparten en toda Latinoamérica.- Por ende al introducir las Empresas Individuales de Responsabilidad Limitada, se busca tener un mismo efecto con las Sociedades Unipersonales sin trastocar su marcos legales y doctrinas aceptadas con algunas diferencias entre cada país.

Costa Rica, que es el referente más cercano a nuestra Legislación, desde el año 1969 mediante el decreto de Ley N4327 del 17 de febrero de ese año, regido según lo dispuesto en el Código de Comercio de Costa Rica en el Libro I, Titulo I, Capitulo II desde el articulo 9 al 16, es uno de los primeros países Latinoamericanos que implementó esta figura de la cual ha sido de gran ayuda para el empuje económico en su sociedad.

En Chile decidió introducir las Empresas Individuales de Responsabilidad Limitada en febrero del año 2003 mediante la Ley $N^{\circ} 19.587$, dicha ley regula esta modalidad en 18 artículos los cuales establecen las pautas de cómo se regirá su constitución, desarrollo, transformación y disolución de las mismas ${ }^{10}$.

En tanto, Colombia anexó la Empresa Unipersonal según lo establecido en el Decreto $\mathrm{N}^{\circ} 222$ del 21 de Diciembre del año 1995 según Capítulo III a partir del articulo 71 al 81 donde se describe minuciosamente su forma de Constitución, requisitos y su manejo.

En Paraguay se establece la Empresa Individual de Respon10 (Lopez y Porras) sabilidad Limitada como un medio para alcanzar fines comerciales y que se reconoce en actividades capitalistas, esto mediante la Ley de Comerciantes del Decreto N 1034/83.- En tanto, Chile y Costa Rica denota una Personalidad Jurídica a la Empresas Individuales de Responsabilidad Limitada lo cual es un claro ejemplo de las primeras concepciones donde solamente se reconoce la constitución de un patrimonio autónomo o de afectación sin darle el elemento de Persona Jurídica o sujeto independiente de derecho.

Chile dio un paso más adelante al hacer una reforma en el 2007 bajo la Ley № 20.190 e introducir las Sociedades por Acciones las cuales pueden ser creadas por una persona, de igual manera ocurrió en Colombia donde en el 2008 con la Ley $N^{\circ} 1258$ introduce la Sociedad por Acciones Simplificadas o (SAS).

\section{INTRODUCCIÓN A LA LEGISLACIÓN HONDUREÑA DE LA SOCIEDADES UNIPERSONALES}

Con el ánimo de reactivar la economía nacional, el Gobierno de la República junto con el Congreso Nacional en apoyo de sectores privados se emitió el decreto legislativo 284-2013 en cual realizan reformas al Código de Comercio vigente, donde en el artículo 5 del mencionado decreto introduce las sociedades unipersonales, no como tales si no al establecer que las sociedades mercantiles creadas en amparo de esa ley podrán ser constituidas por un solo socio.

Así mismo Acuerdo Ejecutivo numero 679-2014 en sus articulados 33 al 36 titulan el capítulo llamado " De los Mecanismos de Toma de Decisión en las Sociedades Unipersonales y las Obligaciones y Responsabilidades del Socio Único" donde se instituye entre otras disposiciones que las facultades de la Asamblea General le corresponden al socio único y otro elemento importante es el registro físico como electrónico de los contratos con el mismo socio único y con terceros que suscriban dichas Sociedades Unipersonales. 


\section{ANÁLISIS DE LA INTRODUCCIÓN DE LA SOCIEDAD UNIPERSONAL EN NUESTRO MARCO LEGAL}

Así las cosas, dicha situación, transforma el panorama jurídico de la visión que se tenía en nuestro marco legislativo relativo a las sociedades mercantiles, puesto que dicho decreto ley en sus 12 artículos que introduce, más los que reforma del Código de Comercio y Código Civil, trastoca la concepción que se tenía en cuanto a la figura societaria en general.

Por lo tanto, dichas reformas no hacen distinción alguna en cuanto a la definición específica de lo que debería entenderse como sociedad unipersonal, a diferencia de otros países latinoamericanos, los cuales han optado introducir esta figura 0 similares.

A nuestro parecer dicha disposición es correcta, ya que al introducir una figura nueva referente a la sociedad mercantil, esta debió instituir las regulaciones o disposiciones que las regirán, y si bien con el Acuerdo Ejecutivo 679-2014 se intenta regular 0 esclarecer algunos puntos vagos que habían quedado en el Decreto ley, sin embargo, aún no se termina de establecer un marco legal donde se proyecte su viabilidad en cuanto a su ejecución empresarial.

No criticamos la decisión de introducirlas a nuestra legislación si no, el poco interés que se les brindó para su explicación o bien, la aparente apatía con respecto a su concepción original puesto que a grosso modo si pretendemos entender esa figura, las Sociedades de Responsabilidad Limitada, Sociedades Anónimas, Sociedades por Comandita Simple Sociedades por Comandita por Acciones y Sociedades Colectivas podrán ser creadas por una persona o Sociedades Unipersonales.

Si concebimos una relación entre lo expresado en el artículo 1 del Decreto 284-2013 donde establece que todas la Sociedades Mercantiles reconocidas por el Código de Comercio y lo antes dicho del artículo 5, entenderemos que las Sociedades Unipersonales tuvieron su concepción y mayor uso en sociedades Capitalistas que de personas, es más, para la concepción de la sociedades de personas sería imposible ser constituidas por una sola, ya que mantienen la característica de dos diferentes clases de socios , o bien no se estipuló al momento de redactar el Artículo 5 del decreto, dejando un vacío que puede acarrear futuros conflictos de interpretación.

Así mismo no se establecieron las regulaciones del caso, en lo que respecta al aseguramiento del capital o patrimonio de la Sociedad.- Es mas según en el mismo Artículo 5 declara que se pueden constituir sin hacer expresa mención al Capital que se invertirá para su creación.

Lo anterior, requiere una análisis especial, ya que si bien es cierto, el objetivo que prima sobre esta figura es la promoción de la inversión, siempre ha sido un punto de discusión el hecho de que las Sociedades Unipersonales posean una especial protección y aseguramiento del Capital con que actuaría para que no incurran en daños a terceros.

Con las obligaciones contraídas en esta clase de Sociedades, debieron ser aplicadas o consideradas en nuestro marco jurídico, tal como se aplicó en otros países, verbigracia, España y Chile donde se establecían los procedimientos internos en que deberían ser llevadas a cabo, con el fin de asegurar el patrimonio de la empresa sin afectar a terceros. En otros casos, ciertas legislaciones arguyen que debe existir un capital inicial y que éste debe ser suscripto en su totalidad por el socio único.

De igual manera si tomamos en cuenta los demás puntos desarrollados en el Decreto, la falta de Publicidad en la Constitución de Sociedades, es en la actualidad un punto toral en la introducción de esta figura, se entiende en otros países que el tercero conozca desde un principio que está celebrando actos de comercio con una Sociedad que sólo tiene o que puede sólo tener un socio como único responsable en cuanto a la representación de la misma.

Podemos percibir entonces que a pesar de ser incorporadas dichas sociedades a fin de alentar al comerciante 0 empresario de invertir en nuestra economía y facilitarle su rápida constitución sin necesidad de esperar las publicaciones o ahorrarle esos costos, también tiende a ser contrario por lo establecido en la doctrina donde se busca en todo momento que la comunidad mercantil, esté consciente de las implicaciones que ésta conlleva.

En cuanto a la posibilidad de llevar los controles o libros de forma electrónica y sin autorización alguna de una autoridad competente, fue previsto en el Reglamento emitido 
bajo el Acuerdo Ejecutivo 679-2014 en su artículo 36 donde menciona que se debe llevar un registro físico así como el electrónico antes mencionado de los contratos suscritos por las Sociedades Unipersonales lo cual brinda mayor seguridad en el manejo de dichas sociedades y de igual forma como antes mencionamos la forma en cuanto a la toma de decisiones en el mismo Reglamento.

Como se estudio, la Sociedad Unipersonal es el beneficio que se le da a una persona natural o jurídica de poder crear otro ente jurídico para actividades de comercio y que este al ser independiente de su creador y por ende hay una separación de sus patrimonios, pero para evitar fraudes 0 daño a terceros siempre se busco blindar o tener mayor control de patrimonio puesto en la sociedad y así mismo evitar su mal manejo para fines ajenos a los de la sociedad y propios del creador para que dichas actividades no fueran del detrimento de la sociedad, lo cual al ser establecidas tantas facilidades en el decreto legislativo 284-2013 pueden ocasionar que esta figura sea bien aprovechada, o por el contrario, sea vista como una amenaza o un peligro hacia las demás entidades de comercio de nuestra país.

En la actualidad se habla de que existen solamente un par de sociedades unipersonales inscritas en el registro mercantil de la cámara de Comercio de Tegucigalpa, lo cual refleja la poca aceptación que éstas tienen, reafirmando que su pobre concepción es condenada a no ser una opción promulgada o recomendada al comerciante que desee emprender un negocio puesto que deja muchas lagunas jurídicas.

\section{RECOMENDACIONES}

A manera de recomendación después de haber realizado la presente investigación consideramos que debería apostársele a este modelo societario, ya que dicha sociedad podría generar beneficios en nuestra Sociedad a fin de incentivar al emprendedor, no obstante, la misma debería formularse a través de un marco legal claro y completo.

Con el ánimo de hacer una crítica sesgada o pretenciosa, resulta justo y necesario que el comerciante pueda entender claramente los alcances, beneficios y responsabilidades que éstas le podrían generar, puesto que no sólo basta con querer incentivar al comerciante interno.
Bajo ese contexto, se recomienda estudiar los modelos de la SAP en Chile y la SAS en Colombia como posibles modelos a implementar en Honduras, puesto que estas reúnen ciertas características que en la actual legislación en el ámbito Mercantil se acomodarían a bien. Es importante considerar para ello algunos elementos como ser, las publicaciones que se realizan para la constitución de Sociedades unipersonales.

De igual manera se trataría entonces de sociedades que por su estructura o concepción no son objeto de modificación al nacer exclusivamente con un socio, o si en algún momento todas las participaciones o acciones recaen en un socio único, como también la incorporación de terceros en ellas. Además por ser creadas en países que primero apostaron por modelos de patrimonios de afectación con personerías jurídicas, han transitado un camino de madurez en la comunidades de comercio por lo cual estas figuras posteriores tienen un alto grado de estudio y si bien es cierto en nuestro país no han recorrido ese camino.

De presentarse la oportunidad, se recomienda también desarrollar un estudio profundizado en estos elementos a fin de comprobar cuál de ellos es el más adecuado para introducirlo en el país, de lo contrario tomarlos solamente como referencia y crear uno similar que se acomode mas a los factores sociales y culturales de nuestra sociedad.

Aparte de esto, se torna necesario analizar o considerar la inclusión de los siguientes elementos: la regulación de su existencia, ya sea como originarias o creadas, como también si éstas deberán reunir algún requisito de publicidad, reconocimiento por nomenclaturas o si la protección o blindaje al capital social deberá ser más específico.

Finalmente, los anteriores elementos, pueden considerarse como los más torales en la en cuanto a la conformación de la Figura de Sociedad Unipersonal tanto por la doctrina y el derecho positivo de los diferentes países estudiados. En ese orden de ideas, se requiere entonces una armonización de factores en consonancia a la realidad de nuestra comunidad mercantil. 


\section{CONCLUSIONES}

- En definitiva podemos decir que las Sociedades Unipersonales son un vivo ejemplo de la relación entre las prácticas y usos comerciales, mismas que deben ser reguladas por el derecho al margen de su concepción tradicional, es decir, que éstas puedan ser manejadas por un sólo socio.

- La sociedad unipersonal constituye una figura que provee múltiples beneficios para una economía que necesita ser atractiva tanto para el inversor interno como el externo.

- Si tomamos en cuenta ciertas directrices, podríamos decir que en general dichas sociedades se contraponen a lo establecido por la doctrina, por lo cual se debe pensar en una reforma que regule exclusivamente esta figura, con el objetivo de que se le genere al inversionista un aire de confianza al incorporase a dicho modelo societario.

- De no subsanarse los vacíos que dicha figura societaria presenta en la actualidad, se estaría sentenciando a que pueda llegar a convertirse en un crónica de una muerte anunciada, debiéndose utilizar para ello las costumbres y usos de comercio como un complemento jurídica a los problemas planteados en el presente artículo.

\section{BIBLIOGRAFÍA}

- Artola Senar, Garazi, (01/07/2012) La Sociedad Unipersonal, Régimen Jurídico. El Derecho Grupo Francis Lefebvre. Recuperado: http://www.elderecho.com/mercantil/sociedadunipersonal-Regimen-juridico_11_430555002.html

- Balmaceda, Maria Isabel. Sociedad Unipersonal o Empresa Individual de Responsabilidad Limitada. Recuperado: http://www.congreso-dmercantil.com.ar/VICAE/ponencias/ Mar\%C3\%ADa\%20lsabel\%20Balmaceda\%20-\%20Sociedad\%20Unipersonal\%200\%20Empresa $\% 20$ Individual $\% 20$ de\%20Resp.\%20Ltda.pdf

- Bonilla Sanabria F. A. (2008), "Unipersonalidad Societaria: A propóstio de un debate actual en el Derecho Colom-
biano.”REVIST@ e - Mercatoria, Volumen 7, Numero 1, 2008 Recuperado: http://dialnet.unirioja.es/descarga/articulo/3627114.pdf

- Castañeda Agredo, Juan Pablo (18 de Abril del 2008). Análisis Histórico-Dogmatico de la Empresa Unipersonal. Revista Virtual "Vía Inveniendi et ludicandi" ( Camino del Hallazgo y del Juicio). Recuperado: http://numanterioresviei.usta.edu. co/articulos/edi4/analisis-historico-empresa\%20unipersonal. pdf

- Código de Comercio de Colombia, Decreto 222 de 1995 - Jequier Lehuede, Eduardo (2011) . Unipersonalidad y Sociedad con un solo Socio; Alcances de su Reconocimiento en la Estructura Dogmatica del Derecho Chileno. Revista lus Et Praxis. Recuperado: http://www.scielo.cl/pdf/iusetp/v17n2/ art08.pdf

- Ley de Sociedades de Capital de España del 2011, Decreto Legislativo 1/2010

- Lopez y Porras, Jaime G. Sociedades Unipersonales. Recuperado: http://www.deforest.mx/system/file.php?id=83

- Troncoso Martinic, Pedro A. La Sociedad Unipersonal en Chile después de la Ley Numero 19.857. Revista Juridica (UCES). Recuperado: http://dspace.uces.edu.ar:8180/xmlui/ bitstream/handle/123456789/180/La_sociedad_unipersonal_en_Chile.pdf?sequence=1 